\title{
Reflections on Deepening College Discipline and Specialty Construction for Post-oriented Education
}

\author{
Youbao Ding \\ Naval Aeronautical and Astronautical University \\ Qingdao, China
}

\author{
Baopeng Li \\ Naval Aeronautical University \\ Qingdao, China
}

\begin{abstract}
Discipline construction is the core of college construction, and it is the key foundation of college teaching and research as well as army service capability and level. The college without key discipline is not key college, and the college without top discipline is not first-class college. This paper discusses several reflections on further deepening college discipline and specialty construction for post-oriented education.
\end{abstract}

Keywords-deepening; post-oriented education; discipline and specialty construction

\section{INTRODUCTION}

Discipline and specialty construction is the foundation for college development, and it is the reflection of school running strength. Post-oriented education of high-level and high quality requires the high-quality discipline and specialty construction functioning as support. With the deepening of a new round of college reform and adjustment, the problems of current discipline and specialty construction for post-oriented education, such as the planning is not systemic enough, the key point is not clear enough, the measure is not powerful enough, and the guidance is not in place, are increasingly prominent.

\section{SIGNIFICANCE OF RECOGNIZING THE DISCIPLINE AND SPECIALTY CONSTRUCTION}

\section{A. Strengthening Discipline and Specialty Construction Is the Internal Requirement for Post-Oriented Education Construction and Development}

Discipline and specialty is the leading factor of college construction and development, of which the construction level is important level for measuring the college's school running strength and talent cultivation quality. As the important component of higher education, army post-oriented education is characterized by high starting point for training, strong job directivity, fast teaching content updating and other features, which needs the frontier discipline theory and practical knowledge, such as the new military theory, new technology and new tactics, and needs the distinctive discipline to function as powerful support [1]. Strengthening discipline and specialty construction, making efforts to create the discipline and specialty platform with distinctive characteristics for postoriented education is the objective requirement to perform post-oriented education well, enhance the comprehensive school-running strength and strengthen the development potential.

\section{B. Strengthening Discipline and Specialty Construction Is the Inevitable Requirement for Deepening the Post-oriented Education Reform}

Since the sixteenth whole army college, the faculty team teaching contents, practical teaching conditions, teaching organization and implementation, the service for army and other transformation construction have made breakthrough progress through overall implementation of teaching evaluation and school-running transformation project. All these are the important component of discipline and specialty construction, laying a solid foundation for promoting discipline and specialty construction at a higher starting point. Currently, with a new round college reform and development, the overall level of college discipline and specialty construction does not entirely meet the requirement of "constantly improving the school-running and education level around realizing the Party's target of strengthening the army under new circumstances" proposed by President Xi, so we shall regard discipline and specialty construction as the core content, important task and strategic target to deepen the postoriented education reform next step. Taking discipline and specialty construction as the lead to integrate and lead various teaching construction work, resolve the deep level problems impacting the post-oriented education development, so as to promote the sound and rapid development of post-oriented education reform and construction.

\section{Strengthening Discipline and Specialty Construction Is the Urgent Demand to Adapt to the Naval Equipment Development}

According to the navy's overall strategic transition requirements, the navy will turn to the shore-based and shipbased combination type from the shore-based model and the equipment assurance has entered into the new stage of leap forward development, as a result, the new and higher requirement will be proposed for teaching, research and the service for army. For this purpose, we shall involve in the new equipment development and styling work deeply, carry out military experts' function of participating in equipment demonstration and control, so as to provide powerful consulting services for higher authority decision-making; we shall follow the development trend of naval aviation equipment closely, plan and carry out teaching capacity building in advance, to posses the ability of undertaking training for installation all new models of equipment and 
equipment modification; the new equipment assurance requirements shall be mastered accurately, being able to guarantee the training method and support equipment that match the construction and development system of army equipment.

\section{IDEAS, CONCEPTS AND METHODS FOR STRENGTHENING DISCIPLINE AND SPECIALTY CONSTRUCTION}

\section{A. Ideas of Discipline and Specialty Construction}

1) Develop the overall planning and top-level design: We shall select the discipline and specialty field (orientation) that the army and colleges urgently need and that having outstanding odds ratio, strong driving effect and good construction benefit according to the principle of "selecting the excellent, needed and effective"; we shall have a view to the new transformation of the generating model of our military's combat effectiveness, make great efforts to integrate the scattered, crossed and repeat specialty around "facing military requirements, aiming at the frontier of the discipline, highlight the advantages and characteristics and focusing on connotation development", so as to reduce the blindness of discipline construction, and overcoming dispersion.

2) Grasp the key points, highlight the characteristics: We shall conduct overall planning to make major breakthrough, follow the military conflict preparation needs, and make efforts to solve the key and difficult issues reflected by the army with attention from the senior officer and the agency badly needs. We shall adapt to the professional characteristic requirement closely in combination with the mission, highlight the teaching training of the mission, study the knowledge, ability and quality required by the post, to construct the discipline and specialty system with distinctive characteristics; we shall firmly establish the guiding ideology of making scientific research serve the fighting capacity generation, make breakthrough in important orientation and major issue, and promote the innovative development of discipline system.

3) Strengthen management, pay attention to benefit: The annual discipline theory and application research plan of this unit shall be developed and the innovation shall be strengthened in combination with the Naval Equipment Security Construction and Development Planning during the "Thirteenth Five-Year Plan" period for various disciplines and majors. In the process of constructing the discipline, colleges shall establish and improve the discipline construction and management agency, strengthen the examination and guidance of discipline construction, so as to discover, coordinate and solve the problems encountered in discipline construction in a timely manner.

\section{B. Concepts of Discipline and Specialty Construction}

1) Strengthen the integrity of discipline construction: The core of college post-oriented education is to cultivate the ability of holding the post. Both teaching and research need the support of multidisciplinary knowledge background; in addition, the scientific development and the basic law of power generation determines the discipline of post-oriented education to develop toward the direction of integration. As a result, reform shall be performed for the discipline and specialty construction to change the simple discipline construction mode in the past, so as to construct by combining talent cultivation, troop construction, scientific research, serving the army, degree program, discipline environment and other factors. Moreover, the academic echelon, material and equipment conditions, teaching and scientific research, carrying out academic exchanges and many other contents shall also be considered.

2) Strengthen the integration of discipline construction: At present, with the development of new army equipment and military innovation, edge discipline, intermediary discipline, interdisciplinary and other emerging military disciplines rise in response to the proper time and conditions, and the implementation of military-political integration as well as command-skill integration will become the main direction of discipline construction for post-oriented education. To create compound and versatile military talents with wide caliber, the limitation between discipline categories, different levels of discipline points, as well as that between discipline category and discipline point shall be broken, to promote the crossintegration of different disciplines, and establish the construction idea of regulating basic discipline and applied discipline, advantage discipline and characteristic discipline relying on each other, and coordinating support and drive.

3) Strengthen the application of discipline construction: The first is to meet the requirement of "qualified for the job". The qualified talents cultivated by the college shall not only possess the excellent operating skills, but also shall be proficiency in equipment theory, having in-depth study of equipment, technology and tactical performance, thus the best combination of person and equipment can be realized and maximize combat effectiveness. Second, expand the function of serving the army. Construct the "comprehensive, proactive, innovative and efficient" service army system, which can settle the key and difficult practical problems occurred in the military equipment support efficiently, and it is the important responsibility of college post-oriented education. The third is to lead the scientific development of the army. The discipline and specialty of post-oriented education college shall not only have the profound theoretical application and research ability, but also can combine the discipline and specialty theory with the army construction application closely, so as to lead the scientific development of army construction in terms of theory research and technology innovation.

\section{Methods of discipline and specialty construction}

1) Make efforts to construct practical discipline system: Post-oriented education focuses on ability cultivation, and strengthening practical course is the only way to realize the cultivation objectives. Therefore, we shall intensify the cultivation view of "capability core", strengthen the 
discipline's practice features and application function with a practical plan, to promote the integration of discipline theory and army practice, and carry forward the discipline innovative development in the practice of post-oriented education. The "problem" awareness shall be strengthened, lead the discipline construction according to the army's practical needs, resolve the realistic problem using discipline theory, and improve the discipline construction level in studying and solving the realistic problem.

2) Construct the comprehensive curriculum system: First, the content shall be integrated. The new course content shall be formed in accordance with certain (such as problem-based, training objective-based etc.) set and internal logic; second, the structure shall be modularized. Decompose the knowledge and skill required by the specific post into some skill courses of different levels using a series of analysis of profession, job, responsibility and mission. Each course module combination corresponds to a group of relevant skills [2]. Third, the setting shall be different. Select the course content and set the course content and structure reasonably starting from the characteristics of corresponding post.

3) Improve the discipline construction mechanism gradually: First, adhere to the academic lead. Give full play to the chief officer's role of consulting and leading in discipline system construction, check and determine the orientation in project approval, tackling the key and difficult problems, as well as the course content reform processes. Second, stick to layer-management. Give full play to the management function of training department, research department, teaching department as well as teaching and research department, so that the discipline and specialty construction may be managed and regulated during its entire process. Third, stick to periodical evaluation. Organize the experts and professors to evaluate the construction status regularly, make comments about it, and regulate the process of discipline and specialty construction.

\section{MEASURES FOR THE DISCIPLINE AND SPECIALTY CONSTRUCTION IN JOB-ORIENTED EDUCATION INSTITUTIONS}

\section{A. Timely Optimize the Setting of Job-orientated Education Specialty}

1) Make adequate investigation and discussion: Seen from internal drives of developing military institutes, the coordinated development between discipline and specialty is a concentrated reflection on the school running orientation and educational theory innovation, which plays a leading role in training job-oriented talents. Institutions should conduct timely discussions and researches on the specialty setting and adjustment, following the principle "overall construction, highlight key points and features, coordinated development", take the discipline and specialty construction as main line, conduct uniform arrangement on the faculty team transition, reform what are taught, create teaching conditions, coordinate the development in academic researches and so on, scientifically planning the overall distribution and development orientation of discipline and specialty construction.

2) Establish specialty layout rationally: Persist in the school running position, create featured brands, intensify specialty advantages, expand the specialty orientation construction, timely adjust the key specialty construction, perfect the specialty system construction, deal with relations between current and long term, external and internal, scientific research and teaching. Firmly follow the functional missions, follow actual conditions in the army, meet the post demand, and follow war environment and well deal with the relations between core military skills and other military constructions.

3) Fully highlight specialty features: Follow and grasp objective laws and find a way with characteristics of its own, which is a significant thought of president Xi. Firmly follow the mission and task, adopt to the requirements of joboriented education, intensify the teaching training of mission topics, closely follow the diverse military tasks under new situations, carefully research the knowledge, capability and quality needed for job-oriented education posts, and build a discipline and specialty system with unique characteristics, and promote the discipline and specialty for construction, innovation and development.

4) Actively expand the specialty inclusion: Follow the specialty construction goal "complete system, accurate position, rational structure, mutual supports in advantages with distinctive features", adapt to the army construction and development need, meet the need of scientific techniques and equipment development, and achieve the "adapt myself to the army development, make myself follow the equipment development". Aim at the specialty development front, focus on the specialty penetration and integration, expand the specialty range, emphasize the inheritance and development of specialty construction, maintain the construction orientation and stabilize the key construction points.

\section{B. Strengthen the Job-Oriented Education Discipline Echelon Construction}

1) Cultivate rational discipline echelons: To keep the discipline and specialty developing healthily needs a discipline echelon with rational structure and actively struggling. So according to the needs of the discipline construction, 1-2 experienced professors who have great accomplishments and influences in the discipline should be cultivated as discipline leaders; according to the research orientations, some middle-aged and young experts who are young and vigorous with wide ranges of knowledge and experience in teaching should be cultivated as academic leaders; according to the requirements of discipline construction, teaching backbone faculties who are competent for teaching with development potentials should be cultivated in order to guarantee adequate successors for the discipline team construction. 
2) Arrange adequate faculties of discipline teaching and research: Set up a concept "Do not require all but make it usable", find a way for horizontal cooperation between institutes and the army, educational institutes and research institutes, engage experts from institutes of the same level or transfer excellent commanders from the army to act as part time researchers, and put the rare knowledge and rich experience they hold into the discipline construction, bring new fresh air to the discipline construction and add new blood; persist in open school running, enlarge the cooperation and exchanges among military or other academies and institutes, open channels to introduce excellent talents from famous military schools or combat troops, set up training bases at army, institutes and military enterprises, and dispatch teachers to further study abroad, for international study or act as visiting scholars, and really speed up the development to top military talents[3].

3) Strengthen to cultivate teachers: First, optimize the structure, try best to set up a faculty team which consists of full time teachers, part time army instructors, civilian servants and specially engaged personnel. Second, strengthen cooperation, push and perfect the mutually cultivation and engagement cooperation mechanism between job-oriented institutes, scientific research institutes in order to form a situation for free flows of faculties; Third, intensify incentive measures, set up the core position of capability construction, and those who have excellent results, find teaching effect and are popular in students shall be amply rewarded, forming a clear policy guide. Fourth, perfect systems, improve the exchange systems between institutes and troops, arrange teachers to attend military training check, comprehensive exercises and large drills, etc; encourage excellent commanders in troops to take a part time teaching in institutes, keep the exchange channels between two parties, promote exchanges with high level academic teams in troops, promote technical cooperation with local institutes, hold high level academic meetings, and raise the discipline and specialty construction quality and level.

\section{Innovate the discipline and specialty work mechanism}

- Foster the disciplinary growing point of job-oriented education, disciplinary growing point is a spring for the sustainable innovation and development of educational institution disciplines. We should aim at the need of navy development strategy and combat, focus on the need of navy and air force equipment construction, guarantee and specialty construction, break through barriers between current disciplines and promote the cross and integration of different disciplines, promote the development and predominant disciplines, growing points of new disciplines and breakthrough of key innovation and form new disciplinary features and advantages. Firmly follow the development research orientation of aircraft equipment security, actively carry out prospective research on aircraft equipment security, support and lead the construction and development of navy aircraft equipment security, and continuously expand new fields for aircraft equipment security.

- Speed up the construction of discipline specialty information resources, information resource is a major foundation and strength mark of discipline specialty construction. A library should fully exert it role as the center of equipment security information center, collect and organize and release information resources related to the equipment security in real time, and provide powerful information service for discipline and specialty construction and troop security training. All discipline and specialty teams should set up professional reference rooms of their own and create an information resources exchange platform. Set up and normalize channels to share resources among military or non-military institutes, research institutes and so on, keep the capabilities of information resources service improved continuously, and drive the academic researches on the discipline and specialty.

- Regularly organize and carry out evaluations on discipline and specialty, the evaluation on discipline and specialty is an overall analysis of the discipline and specialty construction, and an efficient way to improve the discipline and specialty construction level. Institutions shall set up and improve the discipline and specialty evaluation system, analyze and establish evaluation standards, modes and organizational procedures, regularly organize and carry out the discipline and specialty evaluation. All disciplines and specialties should take the evaluation as an opportunity, review the construction of disciplines or specialties of its own, look for deep-level problems that influence and restrict the development, and make targeted correction and construction [4]; follow the thought "Departments mange disciplines, and offices manage specialties", organize and carry out the self evaluation on discipline and specialty, invite experts from the army or institutes of the same level for the evaluation on the discipline and specialty, and find a way of independent evaluation and open evaluation gradually.

\section{CONCLUSION}

Based on the analysis of the significance of discipline and specialty construction for post-oriented education, this article discusses the ideas, concepts and methods of the discipline and specialty construction, and focuses on the effective measures for the discipline and specialty construction. It is hoped that through this study, reference can be provided for the discipline and specialty construction in colleges and universities.

\section{REFERENCES}

[1] Hu Jianxiong, Discipline Organization and Innovation[M]. Hangzhou: Zhejiang University Press, 2001: 243-244.

[2] Liu Xiaoqiang, Peng $\mathrm{Xu}$, Normalize Relations and Break through Corresponding-Thought of Higher Education Discipline, Specialty and Course Reforms [J]. China Higher Education Research, 2010(3): 30-32.

[3] Xuan Yong, Huang Yangjie, Capabilities of Discipline Leader and Discipline Organization Growth—based on Questionnaires of National 
Key Disciplines [J]. Research in Higher Education of Engineering, 2007(6):72-77.

[4] Liao Yi, Research on Evaluation on College Discipline and Specialty [D]. Xiamen University, 2007: 211-219. 